\title{
A LUDIFICAÇÃO NO AMBIENTE VIRTUAL DE APRENDIZAGEM
}

\author{
R.K.A.R.OLIVEIRA ${ }^{1}$, A.N.G.MOREIRA ${ }^{2}$ \\ Universidade Estadual do Vale do Acaraú ${ }^{1}$ \\ Universidade Estadual do Ceará ${ }^{2}$ \\ antonionilson2005@gmail.com²
}

Artigo submetido em 25/06/2017 e aceito em 21/07/2019

DOI: $10.15628 /$ holos.2019.8240

\section{RESUMO}

$\mathrm{O}$ ambiente virtual de aprendizagem (AVA) consiste em locus onde se processa grande parte das interações professor-aluno e aluno-aluno em cursos de Educação a Distância (EaD). Todavia, tem se percebido que esses espaços ainda são disponibilizados aos cursistas com forma e aparência que podem ser caracterizadas como fria, estática e pouco envolvente, carecendo de elementos que os tornem mais atrativos aos cursistas. Diante dessa constatação, esta pesquisa analisa a ludificação como uma das diversas estratégias pedagógicas que podem ser aplicadas ao AVA, objetivando apontar técnicas que venham a ser significativas para melhorar a qualidade da interação com o objeto "exercício". A análise foi desenvolvida a partir do AVA da Universidade Estadual do Ceará, em seus cursos de EaD, e ainda com pesquisa de cunho bibliográfico, por autores que desenvolveram a ideia de ludificação. Foram identificadas sete técnicas: pontos de experiência; pontos de habilidade; pontos de carma; níveis do jogo; narrativa; desafios (missões); e medalhas (conquistas) as quais, inseridas no AVA, poderão contribuir para a interação e a aprendizagem dos educandos.

PALAVRAS-CHAVE: Ludificação, Ambiente Virtual de Aprendizagem, Educação a distância.

\section{GAMIFICATION IN THE VIRTUAL LEARNING ENVIRONMENT}

\begin{abstract}
The virtual learning environment (VLE) consists of locus where a large part of teacher-student and student-student interaction takes place in Distance Education courses mode (EaD). However, it has been noticed that these spaces are still available to the students with form and appearance that can be characterized as cold, static and poorly involving, lacking elements that make them more attractive to the students. In view of this finding, this research analyzes gamification as one of several pedagogical strategies that can be applied to VLE, aiming at
\end{abstract}

pointing out techniques that may be significant to improve the quality of interaction with the "exercise" object. The analysis was developed from the VLE of the State University of Ceará, in its courses of EaD, and also with bibliographic research, by authors who developed the idea of ludification. Seven techniques were identified: experience points; Skill points; Points of karma; Game levels; narrative; Challenges (missions); and medals (achievements) which, inserted in the AVA, can contribute to the interaction and learning of learners.

KEYWORDS: Gamification, Virtual Learning Environment, Distance education. 


\section{INTRODUÇÃO}

A Educação a Distância (EaD) é uma nova modalidade global de ensino, mais célere, integrativa e multimidiática. Utiliza os meios de comunicação (televisão, rádio, internet etc.) para levar o ensino aos pontos anteriormente isolados geograficamente, proporcionando o acesso e a democratização da mesma.

Novos paradigmas pedagógicos são plenamente viáveis na EaD, visto que a própria tecnologia de informática utilizada como base para este tipo de ensino permite o uso de recursos pedagógicos variados, inclusive a utilização de jogos interativos, por exemplo.

O ambiente virtual de aprendizagem (AVA), espaço virtual através do qual grande parte das interações se efetiva, foi desenvolvido para oferer conteúdos à distância, disponibilizar ferramentas síncronas e assíncronas de fácil manuseio e compreensão, a fim de facilitar o aprendizado.

O AVA disponibilizado aos estudantes dos cursos ofertados via EaD pela Universidade Estadual do Ceará (UECE) possui uma ferramenta educacional chamada "exercício", tratando-se este de um formulário virtual com questões de múltipla escolha. Mesmo com esse instrumento para favorecer a memorizarização do conteúdo teórico estudado, a metodologia somente foi transferida do papel para a tela do computador, repetindo o que tradicionalmente vem sendo utilizado nas aulas presenciais. $\mathrm{O}$ aluno apenas marca a opção que achar correta e ao terminar de responder todas as questões, envia para correção, que é automática.

Nessa situação, não há diferença entre responder um questionário impresso na aula presencial ou responder o questionário virtual, já que em ambos os casos o aluno apenas verificará se assimilou o conteúdo estudado. Todavia, este não deve ser o propósito da educação em plataformas virtuais, posto que a tecnologia digital deve ser empregada para estimular o engajamento, a criatividade, 0 senso crítico e a percepção da utilidade prática daquilo que foi aprendido na teoria. 
Frente à nova realidade da educação e diante da possibilidade de analisar a viabilidade de inclusão da ludificação em plataformas de educação a distância, viu-se a oportunidade de identificar proposta conceitual adequada para auxiliar na remodelação de uma ferramenta pedagógica, apontando técnicas de ludificação que acredita-se serem as mais significativas para alterar o objeto de análise escolhido para este trabalho, qual seja, a ferramenta "exercício" do AVA da UECE.

Prentede-se, com este trabalho, identificar técnicas de ludificação viáveis para uma possível remodelação da ferramenta educacional "exercícios", contida no AVA da UECE, que a tornarão mais representativa na educação auto-orientada do aluno. Especificamente prentende-se demonstrar, ainda, a importância da ludificação no processo de aprendizagem.

O trabalho está estruturado em mais quatro tópicos além desta introdução. No primeiro foi feito um resgate dos referenciais teóricos utilizados, onde, partindo-se do ambiente virtual de aprendizagem (Fardo, 2013; Carvalho, 2006; Munhoz, 2013), resgatou-se elementos da teoria dos jogos (Bierman, 2011), e contribuições desta para a ludificação (Rau, 2012; KIM; Lee, 2013).

Em seguida são apresentados a metodologia, com predomínio de pesquisa bibliográfica, a análise dos dados e as considerações finais. O trabalho se justifica pelo grande desafio que a educação a distância tem em estimular o aluno a regressar ao AVA e interessar-se cada vez mais pelo seu curso, oferecendo-lhe uma formação de qualidade. Nessa perspectiva, vislumbrou-se a necessidade de remodelação dos exercícios ofertados, introduzindo a ludificação nessa ferrametna a partir das técnicas recomendadas.

Anunciados os componentes mais gerais deste artigo, a seguir são apresentados os pressupostos teóricos utilizados.

\section{MARCO TEÓRICO}


Este tópico está oganizado em três blocos. No primeiro é retomado o contexto do problema, o ambiente virtual de aprendizagem, sendo este considerado como a sala de aula da sociedade contemporânea. É feita uma problematicação do AVA da Universidade Estadual do Ceará, onde é tecida uma crítica a uma de suas ferramentas, a denominada 'Exercício', na perspectiva de sua requalificação. Em seguida vai-se buscar na teoria dos jogos elementos que justificam uma reformolulação. Adiante consta o registro da busca e a proposição de técnicas de ludificação adequadas ao referido ambiente.

\subsection{Sala de aula no século XXI: o ambiente virtual de aprendizagem}

Podode-se definir instituição educacional como um centro de ensino e aprendizagem, um ambiente onde se transmite conhecimento, capacitando pessoas. Durante os séculos XIX e XX essas instituições eram as grandes responsáveis pela formação instruncional das pessoas, o que tornava a educação uma atividade centralizada em poucos espaços. Todavia, esta não deve limitar-se a um conceito único, nem tampouco centralizada, ou nas mãos de poucos, como defende Marcelo Luis Fardo (2013):

A educação é uma zona de interação e intersecção entre diversos campos de trabalho e pesquisa, articulada com áreas como a tecnologia, a sociologia, a comunicação, a linguística, a antropologia, a psicologia e a filosofia. Vista como principal pilar da formação humana, a educação é um fenômeno universal, de certa forma natural e até instintivo (os pássaros ensinam seus filhotes a voar ao expulsá-los do ninho, educando-os para a vida), e de fundamental importância na evolução da espécie humana. Através dela, o homem assegura a continuidade dessa evolução como espécie pensante e construtora de conhecimento, o que garante que esse processo siga em frente e não tenha que ser sempre recomeçado. Muitas vezes, a educação é tida como caminho (se não o único, certamente um dos mais promissores) que conduz a um futuro utópico marcado pelo progresso e consolidação de ideais como a paz mundial, a justiça social e a igualdade entre os povos. É impossível atribuir um único ator ou instância à tarefa de educar (p. 25).

Embora a educação tenha sido determinada, no Brasil, como responsabilidade do Estado e, por isso, muitas escolas e universidades se espalharam pelo país, não foi possível chegar a todas as localidades pela simples inviabilidade, e financeira e geográfica, restando a muitas pessoas a 
inconclusão dos estudos, ou até mesmo, o analfabetismo. Em muitos Estados, geralmente, somente as capitais, especialmente as maiores e mais desenvolvidas, realmente desfrutavam plenamente do acesso à instrução e capacitação.

Entretanto, globalmente, com o avanço da tecnologia da computação e a criação da rede de computadores após a década de 1960, criou-se uma interligação que possibilitou a difusão de conhecimento de forma mais fácil e célere, diminuindo as distâncias e aumentando a velocidade da evolução científica. Mas foi a partir dos anos de 1990, com a expansão e popularização da rede mundial de computadores, denominada então de internet, que a educação sofreu consideráveis mudanças, aumentando o acesso às informações e mitigando as barreiras geográficas, inclusive no Brasil (Carvalho, 2006).

Com a internet, surgiram páginas (sites) com conteúdos educacionais variados, livros digitais e, por fim, cursos de capacitação (técnicos, tecnológicos, de graduação ou de pós-graduação) com uma nova modalidade de sala de aula, que é o ambiente virtual de aprendizagem. Este é apresentado com maestria por Antônio Siemsen Munhoz (2013), como segue:

A evolução tecnológica e o surgimento do maior fenômeno de comunicação de todos os tempos, a internet, cria locais onde proliferam informações educacionais e orientações de estudos que possibilitam às pessoas com capacidade para aprendizagem independentes condições de aprender. Esses locais são conhecidos sob diversas denominações, que podem ser englobadas como ambientes virtuais de aprendizagem, em que é desenvolvida a inovadora abordagem do ensino a distância por meio eletrônico (p. 21).

Deve-se destacar neste ponto que a internet trouxe uma nova concepção de ambiente de aprendizagem, sendo este completamente inédito na história da educação. Deve-se elucidar que espaço é todo ambiente capaz de criar interação social e construção de significados para as partes envolvidas. Logo, os ambientes virtuais não pretenderam copiar o espaço físico real existente, mas criar uma nova ideia de experiência espaço-temporal.

Isto é fundamental para que haja a comunicação entre as pessoas, pois a socialização e troca de conhecimento, nas salas de aulas presenciais, ocorre por meio de interações e compartilhamentos 
de materiais e objetos, ou seja, sempre que o professor utiliza o ambiente físico, o quadro e os livros, por exemplo, ele está transmitindo o conhecimento através de meios tangíveis, sendo tanto o local existente como os itens utilizados componentes do recinto físico de educação.

Como tudo é imaterial e intangível na educação virtual, o ambiente de aprendizagem deve conter ferramentas capazes de despertar no aluno o interesse pelo aprendizado e efetivamente transmitir a informação. Assim, a sala de aula caracteriza-se pela interação somada ao espaço e isto confere valor e significado para o meio virtual, que supera a existência tangível do local de ensino e dos objetos utilizados na educação presencial (Almeida, 2014).

O que se observa na prática é a inserção de novos instrumentos para realizar ações já conhecidas e bem aceitas no ambiente educacional tradicional, como por exemplo, a conversa em sala de aula com o professor ocorre pessoalmente, o que no ambiente virtual de aprendizagem pode ser feito por meio de salas de bate-papo, troca de mensagens, e-mail etc.

As aulas expositivas podem ser ministradas por vídeo conferência, as tarefas tornam-se virtuais, os trabalhos realizam-se em equipe ou individualmente na própria plataforma do ambiente virtual, ou seja, praticamente tudo que ocorre na educação presencial pode ser reproduzido satisfatoriamente no AVA e de uma maneira totalmente diferente, com ferramentas exclusivas para esta modalidade de ensino.

Assim, percebe-se que o AVA foi desenvolvido especificamente para ser um ambiente educacional, oferecendo conteúdos à distância, disponibilizando ferramentas síncronas e assíncronas de fácil manuseio e compreensão, cuja única finalidade é facilitar o aprendizado. Além disso, esses ambientes também viabilizam para o professor a transmissão do conteúdo, já que este deixa de ser a única fonte de origem do conhecimento a ser aprendido, interagindo com novos saberes (Fardo, 2013).

Cada AVA é desenvolvido de acordo com uma finalidade específica, para um público próprio, com objetivos e propósitos preestabelecidos, todas as informações nele disponibilizadas são apresentadas de acordo com um plano pedagógico singular e técnica psico-educacional direcionada para a sua finalidade, com vista a possibilitar a interação e comunicação entre todos os envolvidos. 
Diante desse diferencial técnico, o ambiente virtual acaba por influenciar o próprio docente, que na educação à distância possui uma postura multifocal em relação à transmissão do conteúdo, pois estabelece uma dialogicidade entre informação, conteúdo, plataforma virtual e discente. Saliente-se também, que o processo comunicativo deve ser claro e conciso, pautado em ações planejadas e organizadas, com a finalidade de atender às reais necessidades da proposta de ensino (Santinello, 2015).

\subsection{Jogos, interação e ludificação}

Os elementos de jogos estão diretamente associados aos desejos humanos, como por exemplo: os pontos ganhos em um jogo refletem a necessidade de reconhecimento social; os níveis de evolução do jogador são uma forma de demonstrar status social; os quadros de liderança suprem a necessidade de competição que as pessoas possuem; os presentes e bônus compartilhados estimulam o altruísmo humano, etc. (Bbva Innovation Edge, 2012).

No âmbito educacional há inúmeros exemplos de sucesso com o uso de ludificação, como o Livemocha, que é um site para estudos de idiomas onde os membros cadastrados interagem mutuamente para aprender e ensinar idiomas. Este sítio da internet usou a teoria dos jogos para fidelizar seus participantes, ou seja, fazê-los visitar periodicamente suas páginas e assim contribuir para a manutenção do mesmo. Os participantes neste caso são incentivados através de um sistema de pontuação e insígneas.

O participante do Livemocha ganha pontos em cada ação dentro do sítio, como no caso de realizar exercícios, corrigir redações de colegas, solucionar desafios, etc. Cada ausuário, à medida que avança em suas tarefas, eleva-se socialmente perante os demais participantes, sendo premiado com insígneas (no caso, moedas de ouro do sítio) e com a liberação de atividades complementares do idioma que está aprendendo (Quadros, 2013). 
Desde a infância todas as pessoas estão constantemente jogando, seja manipulando setimentos próprios, dos outros, ou simplesmente divertindo-se de forma criativa. Jogar é um meio de interação social tão antigo quanto a própria organização da sociedade. Como a competitividade e a ambição são características intrínsecas e comuns a todos os seres humanos, os desafios em forma de jogos tornaram-se uma forma de diversão e distração para as pessoas, levando inclusive ao vício em alguns casos extremos.

Diante do notório interesse humano por este tipo de interação social e de sua capacidade de influenciar e fidelizar seus participantes, logo o meio acadêmico interessou-se por estudá-lo, sendo as pesquisas matemáticas as que mais se destacaram neste sentido. Com o intuito de se obter um padrão de ação e reação humano durante as partidas, esta ciência passou a estudar situações nas quais um tomador de decisão necessite considerar a ação dos outros. Este estudo denomina-se de teoria dos jogos.

Segundo essa teoria, em um ambiente de competição intelectual associada a jogos, os participantes são desafiados a desenvolverem um raciocínio mais célere, para solucionar problemas com o melhor retorno possível. Perecebe-se que o intuito é analisar o modo como os indivíduos (jogadores) tomam decisões quando estão cientes de que as suas escolhas influenciam diretamente o resultado do jogo e as escolhas dos demais participantes. Pode parecer algo subjetivo, mas na realidade é pura lógica matemática, já que os jogadores seguem padrões de raciocínio (Bierman, 2011).

Outra etapa percorrida na evolução da teoria dos jogos foi o estudo dos sentimentos vinculados ao comportamento humano, sendo uma de suas vertentes a ludificação. Esta é também conhecida como gameficação ${ }^{1}$, que é um processo de pensamento e mecânica de um jogo aplicado a uma situação real, seja ela profissional ou educacional.

Juntando-se os avanços nas pesquisas sobre a ludificação ao fato público e notório de que as pessoas gostam de jogos e se interessam por eles em algum momento da vida, a partir da década de

\footnotetext{
${ }^{1}$ A palavra gamificação é considerada um barbarismo em língua portuguesa, ou seja, sua escrita e pronúncia é um erro por sua inexistência no referido idioma. O radical latino para jogo é "ludi", sendo assim em todas as demais línguas românicas como o francês, italiano, espanhol, etc. Por este motivo esta palavra não será adotada no presente trabalho.
} 
1990 foram realizados vários estudos sobre a possibilidade de utilizá-los em ambientes corporativos e educacionais, tanto para treinamento como para desenvolvimento da criatividade. Essas pesquisas levaram ao desenvolvimento de uma ciência educacional específica para aplicação de games na aprendizagem, chamada de Digital Game-Based Learning (DGBL) (Eck, 2006).

Não adentrarse-á, neste trabalho, nos conceitos da DGBL. Esta foi citada apenas para indicar como a educação tem sofrido inúmeras alterações ao longo dos séculos XX e XXI, sendo a EaD a sua mais recente e diametral inovação.

Este trabalho baseia-se na concepção construtivista da aprendizagem sob o prisma das inovações tecno-pedagógicas na área educacional. Isto implica dizer que, partindo do pressuposto da teoria construtivista que afirma ser o conhecimento uma consolidação oriunda de auto-regulações estabelecidas entre o sujeito que aprende e o objeto de estudo (Klock, Carvalho, Rosa e Gasparini, 2014), iniciou-se este estudo centrando-se na análise do ambiente virtual de aprendizagem da UECE e uma de suas ferramentas pedagógicas, utilizada como tecnologia digital de apoio ao aprendizado.

A utilização de recursos digitais influencia positivamente no desenvolvimento da educação tanto do ponto de vista do aluno quanto do orientador, vez que incentiva a criatividade e facilita o acesso a ferramentas e serviços que ampliam a troca de conhecimentos e a colaboração mútua (Fardo, 2014).

Entretanto, problemas relacionados à motivação e ao engajamento dos estudantes ainda persistem nos ambientes virtuais e entende-se que estes espaços são pensados e destinados para que os processos de ensino e aprendizagem aconteçam, não para desmotivarem os alunos. Por isso, a ludificação pode ser uma solução para esta situação tão recorrente, que desafia os educadores.

\subsection{A necessidade de ludificação para o AVA EaD da UECE}


A EaD é inovadora em muitos aspectos, pautando-se especialmente no desenvolvimento do auto-didatismo, o que exige dos alunos muita disciplina, comprometimento com o aprendizado e próatividade.

Sendo a educação brasileira ainda baseada em um modelo clássico de dependência do professor como único detentor do conhecimento e única fonte de aprendizado direto, torna-se difícil adaptar os alunos à EaD, pois esta modalidade de ensino exige uma completa remodelação mental do que é estudar e aprender.

Nesse sentido, a ludificação é uma maneira simples de atrair o estudante para o AVA e desenvolver, de forma imperceptível para ele, as habilidades necessárias para aprender através de EaD. Por definição, a palavra lúdica vem do latim ludus e seu significado é brincar, divertir- se, jogar. Diante desta breve definição, percebe-se que incluir este conceito na educação é na realidade tornála mais divertida e interessante para aqueles que estão diretamente engajados com a aprendizagem, sejam docentes ou discentes.

Embora possa parecer que a ludificação é um fenômeno recente, visto que deriva diretamente da popularização dos jogos eletrônicos e de sua capacidade de reter a atenção dos jogadores, na realidade, a apropriação do jogo pela escola é um fato bem mais antigo, pois muitos autores defendem que na Roma e Grécia antigas, doces já eram produzidos em forma de letras e destinados ao aprendizado da escrita, em uma espécie de quebra-cabeças ou caça-palavras (Rau, 2012).

Este evidenciamento da ludificação, entretanto, só ocorreu com a revolução computacional, pois os jogos eletrônicos tornaram-se uma forma de entretenimento global e estão presentes em inúmeros tipos de computadores (tablets, desktops, notebooks, celulares etc.), motivando seus jogadores a solucionar problemas (evolução de fases do jogo) e potencializando suas aptidões. Como afirmam Martins, Nery Filho,Vieira e Pontes (2014):

Segundo a ACl Games3 (Associação Comercial, Industrial e Cultural de Games), em pesquisa realizada em 2012, os jogos de videogame representam hoje, em todo o mundo, o maior mercado de entretenimento, superando a indústria do cinema e da música juntos. De acordo com Fardo [2013], nos Estados Unidos, praticamente todas as residências possuem algum dispositivo capaz de rodar games comerciais, metade 
das casas possuem um dispositivo dedicado somente aos games (consoles) e a idade média dos jogadores é de 30 anos. No Brasil, segundo a Pesquisa Game Mobile Brasil-20134, 41\% das mulheres e $59 \%$ dos homens declaram jogar algum game, em multiplataformas (p.22).

Essa intimidade com os jogos e o mundo virtual estimulou a sua aplicação também em ambientes reais, como método aplicado em programas de marketing e aplicações para web, com a finalidade de motivar, engajar e fidelizar clientes e usuários (Zichermann, Cunningham, 2012).

Assim, pode-se afirmar que a ludificação pressupõe a utilização de elementos tradicionalmente encontrados em jogos, como: uma história narrativa; sistema de resposta (feedback); sistema de recompensas; conflito; cooperação; competição; objetivos e regras claras; níveis; tentativa e erro; diversão; interação; interatividade etc. (Kloc et. al., 2014).

O emprego dessas técnicas de jogos é para incentivar um comportamento, o que certamente é muito interessante para o âmbito educacional, especialmente nos cursos à distância. Com fulcro nisto, verifica-se que, diante do fato de a UECE ofertar cursos na modalidade à distância, sendo estes ministrados parcialmente no ambiente virtual de aprendizagem (AVA) e parcialmente de forma presencial, é plenamente possível e viável utilizar a técnica da ludificação para melhorá-los.

Em análise desse AVA, verifica-se que muitas atividades são elaboradas pautando-se em técnicas pedagógicas tradicionais, ou seja, são uma mera reprodução do que já se utiliza no ensino presencial, sem acrescentar nenhuma inovação metodológica que concilie a evolução pedagógica com o desenvolvimento tecnológico.

Assim, é de fácil constatação que os cursos à distância da UECE não incluem a ludificação como forma de reter a atenção do aluno e instigar a competitividade, altruísmo e disciplina, o que é preocupante, já que essa metodologia é de alta relevância para o aprendizado.

No contexto educacional, a gamificação tem sido amplamente discutida, sendo reforçada a idéia, por muitos pesquisadores, de que o processo não é apenas a adição de medalhas, pontos e recompensas e tampouco uma atividade para trivializar o processo de aprendizagem, mas deve ser usado metodicamente nas situações em que for apropriada, consistindo em um processo trabalhoso e cuidadoso [9][10]. Assim, a convergência entre ensino e gamificação tem se apresentado como um novo desafio, na medida em que são necessários critérios bem definidos na escolha dos elementos dos games 
que sejam apropriados aos diversos segmentos de atividades pedagógicas com vistas a motivar a resolução de problemas e encorajar a aprendizagem, tendo em mente que nem todas as características da gamificação podem ser utilizadas em todas as situações de ensino e de aprendizagem (Roque, Santos, Geiss, 2013, p. 677).

Portanto, não basta utilizar um meio tecnológico moderno para se ofertar uma educação de maior qualidade e mais proveitosa para o aluno. Na realidade, a teconolgia pouco ou nada contribuirá se a metodologia pedagógica for obsoleta ou inadequada. Pode-se facilmente cometer o equívoco de crer na plena eficácia do ensino quando na realidade a tecnologia ofereceu apenas eficiência no acesso à educação, sem acrescentar nada em termos de melhoria cognitiva para o aluno.

Para assegurar que a ludificação aumenta o aprendizado do aluno, dois cientistas coreanos, Jung Tae Kim e Won-Hyung Lee, em 2013, criaram uma fórmula matemática para análise da dinâmica da ludificação na aprendizagem, ou seja, através desta equação é possível verificar o desempenho da teoria dos jogos no aprendizado do aluno, descobrindo-se assim se realmente esta técnica deve ser utilizada em um determinado plano pedagógico. Conforme afirmam os retrocitados autores:

\begin{abstract}
The core idea of the model for educational effectiveness through Gamification as a function of time, $x(t)$, initiates the comparison with an assumption of educational effectiveness of traditional learning. Assume that the educational effectiveness of the traditional way is solid but steady which is why it is assigned a constant value, ETW. The dynamical model initially starts with a lower educational effectiveness than the traditional way. Thereafter the educational effectiveness increase rapidly and exceeds the educational effectiveness of traditional learning and converges with learning capacities (Kim, Lee, 2013, p.179-180).
\end{abstract}

Verifica-se que a ideia central deste modelo matemático gira em torno da eficácia educativa com a ludificação em função do tempo, iniciando-se a comparação com um índice ou marco inicial (número inicial) já estabelecido na aprendizagem tradicional. Este índice é um valor considerado ideal ou satisfatório quando se verifica a aprendizagem do aluno, ou seja, é uma nota, por assim dizer, que gradua baixos e altos desempenhos.

Os coreanos partiram do pressuposto de que já existe um método de avaliação de desempenho tradicional sólido o suficiente para Ihes fornecer bases matemática comparativas. Estas são indicadores de eficácia constantes, e por isso, a verificação da educação com influências da 
ludificação iniciou-se com um valor menor do que a educação tradicional, para ter-se uma curva gráfica de melhor visibilidade.

Os fatores verificados foram a eficácia educativa dos métodos tradicionais, o tempo final avaliado (último ponto de leitura da avaliação), o elemento fantasia (que também pode ser entendido como a criatividade no aprendizado), o desafio (as tarefas dos alunos), a curiosidade (desejo de aprender) e a taxa de crescimento efetiva da educação através da ludificação.

Uma vez aplicada a equação em uma situação fática, percebeu-se que métodos educacionais com ludificação superam, em termos de desempenho de aprendizado, facilmente os métodos de educação tradicional. No caso da alfabetização de alunos, por exemplo, a quantidade de palavras aprendidas é 25\% maior quando há emprego da ludificação no ensino (Kim; Lee, 2013).

Diante da comprovação matemática de que a ludificação efetivamente aumenta o aprendizado do aluno, mister se faz a inclusão desta metodologia nos cursos da UECE, em especial, nos baseados em educação à distância.

Para que esta inclusão seja possível, deve-se primeiramente estabelecer os três elementos fulcrais mínimos da ludificação, que Moreno, Pineda e Montoya (2014) afirmam serem as mecânicas do jogo, as dinâmicas do jogo e os componentes do jogo. De acordo com o autor, tem-se a definição de cada um destes, in verbis:

Mecánicas de juego: De acuerdo a [12], estas mecánicas hacen referencia a la serie de reglas que intentan hacer el sistema más interesante y se pueda disfrutar, según este autor se debe buscar reglas que generen una grado de 'adicción' y compromiso por parte de los usuarios, esto según el autor le aporta a las personas, una guía por la cual transitar ya sea en un videojuego, o en cualquier tipo de aplicación. Según [9], algunas de las mecánicas más comunes y más efectivas son usadas en la gran mayoría de los juegos son: retos, oportunidades, competición, cooperación, feedback, transacciones, turnos, puntos, niveles, entre otros.

Dinámicas de juego: De acuerdo a [9] estas dinámicas hacen referencia a todos los aspectos globales que se espera el usuario perciba durante un curso ludificado, en otras palabras, está relacionado con los efectos motivacionales que se esperan tengan los participantes. Según este mismo autor las dinámicas que se generalmente se buscan en los juegos son principalmente: recompensa, estatus, logro, autoexpresión, competencia, altruismo,

Componentes de juego: De acuerdo a [9] estos componentes hacen referencia a las instancias específicas de las dinámicas y las mecánicas de juego dentro del juego, así las dinámicas y las mecánicas no son visibles los componentes si lo son para los usuarios dentro de los juegos. Algunos de los 
componentes más utilizados dentro de los juegos se puede mencionar a los: logros, avances, desbloqueo de contenido, regalos, conquistas, desafíos, rankings entre otros (p.463).

Percebe-se assim que estabelecer estes elementos é garantir que a ferramenta educacional com ludificação será capaz de prender a atenção do aluno, fidelizar sua frequência no curso, trabalhar sua autoestima e sociabilidade e por fim, tonar a ferramenta interativa e divertida. Isto posto, o próximo passo é o planejamento de um modelo a ser implementado.

Este deve ser capaz de aumentar o número de acessos do usuário, ou seja, o aluno deve voltar várias vezes ao AVA para interagir com a ferramenta educacional, além de motivar o estudo e prática do curso. A memorização de teorias e a compreensão do conteúdo devem estar tão presentes na interação diária com a ferramenta que se torna sutil e espontâneo o aprendizado.

\section{PROCEDIMENTOS METODOLÓGICOS EMPREGADOS}

Para a realização deste trabalho foi desenvolvida uma pesquisa bibliográfica, cujo procedimento basilar foi a leitura de publicações científicas a partir de 2011 até 2015.

A primeira etapa da pesquisa foi a leitura exploratória, onde foi realizada uma consulta no âmbito acadêmico-científico para identificar possíveis obras e artigos de interesse para o estudo em tela.

O próximo passo foi a leitura analítica, que consistiu na organização das informações contidas nas fontes consultadas, através de uma avaliação de natureza crítica. Nessa etapa do procedimento, realizou-se a leitura integral dos textos selecionados para adquirir uma visão abrangente do contexto da pesquisa.

Seguindo-se a isto, ocorreu a identificação das ideias principais do tema e a hierarquização destas, pois se fez necessário organizar de forma sistemática todas as informações obtidas de acordo com a ordem de relevância para o desenvolvimento do objeto desta pesquisa. 
Após a leitura completa das obras selecionadas, pautou-se o desenvolvimento e conclusão no método dedutivo, ou seja, comparando as técnicas de ludificação encontradas com a ferramenta escolhida para análise, foram escolhidas sete técnicas que se acredita serem as mais indicadas para a reformulção do objeto pedagógico em questão.

Este estudo pode situar-se ainda como de nível exploratório, posto que, foi fornecida apenas uma visão geral do tipo aproximativo, que apontou a melhor relação provável entre os recursos de ludificação e a ferramenta exercício, ficando para posteridade a aplicabilidade prática em programação para o modelo aqui indicado.

\section{ANÁLISE DE DADOS}

A apreciação do material coletado procedeu-se mediante análise de conteúdo. Com o relacionamento dos modelos de ludificação encontrados à ferramenta objeto deste estudo, foi possível identificar técnicas que se acredita serem as mais adequadas para futura implementação no objeto "exercício", via programação.

As informações obtidas foram organizadas em ordem de relevância para a ferramenta, sendo excluídas as técnicas de ludificação que fossem de grande complexidade para interagir com o aluno, as que exigissem computadores servidores de perfórmance muito elevada e as que fossem de difícil programação.

O critério de relevância foi definido em consonância com níveis já estabelecidos cientificamente que indicam o grau de envolvimento dos usuários de ferramentas com ludificação. Alguns destes indicadores apontam para a sensibilidade em relação a certos fatores, como, por exemplo, o desafio do jogo, a fantasia e a curiosidade, que varia de acordo com a idade e o gênero (Kim, Lee, 2013). 
A ferramenta indicada neste trabalho, como mais propícia à implementação das técnicas aqui apontadas, é o exercício ao final de cada disciplina. É imperativo elucidar previamente que se trata este de um tipo de formulário on line não lúdico, onde o aluno marca as alternativas que julgar corretas e as envia ao sistema. Este, por seu turno, automaticamente atribui a nota ao mesmo.

Para melhorar a ferramenta 'Formulário' acredita-se ser necessária sua remodelação. Por isto, sugere-se aqui uma proposta para auxiliar nessa reformulação e, dentre as muitas analisadas, sugerese algumas técnicas de ludificação que e adequam ao perfil da ferramenta. São estas: pontos de experiência; pontos de habilidade; pontos de carma; níveis do jogo; desafios e missões do jogo; medalhas e narrativas.

De acordo com Clock et. al. (2014), é possível delinear cada uma destas em breves conceituações, como segue:

Pontos de experiência: Também conhecidos como XP, é o mais importante sistema de pontos, não serve como moeda de troca no sistema, todas as ações do jogador geram XP e uma vez adquirido ele não os perde. Apesar disso, em alguns sistemas, pontos podem expirar e/ou serem trocados. O objetivo principal é observar, classificar e guiar o usuário sobre o seu comportamento. Uma característica importante é que normalmente o sistema não possui um limite máximo de pontuação;

Pontos de habilidade: Também conhecidos como pontos skill, são atribuídos a tarefas específicas, que não estão relacionados às atividades principais do sistema. O usuário pode optar por realizá-las ou não, e são um conjunto bônus de pontos que permitem que o usuário ganhe experiência ou recompensas pela realização;

Pontos de carma: São pontos que pertencem ao usuário e que ele pode compartilhar com outra pessoa. Este é o propósito deste tipo de ponto, fazendo com que o usuário seja beneficiado somente se existir compartilhamento entre as partes. Seu objetivo é criar um caminho comportamental para o altruísmo e recompensa entre usuários incentivando o compartilhamento dos pontos;

Níveis de jogo: Espera-se que um sistema de níveis de jogo atenda três objetivos principais. O primeiro é manter a percepção de que há progresso na história do jogo/sistema, proporcionando o engajamento do usuário. Fazendo essa relação com os ambientes educacionais, espera-se que os estudantes percebam seu progresso no processo de ensino-aprendizagem. O segundo é focado no desenvolvimento das habilidades do usuário e visa que a cada nível avançado, habilidades aprendidas sejam reforçadas ou novas sejam aprendidas, gerando aprendizagem gradativa. Por último, os níveis servirão como motivação para os usuários pois, ao avançar de nível, ele vai querer alcançar os novos objetivos do nível atual e avançar para níveis mais difíceis;

Desafios e Missões: Os desafios e missões são os elementos que orientam os usuários sobre as atividades que devem ser realizadas dentro de um sistema (Fadel et. al, 2014), (Zichermann e Cunningham, 2011). É importante que existam desafios para os usuários completarem, pois isso fará com que exista algo interessante para ele realizar enquanto interage com o sistema. Alguns usuários vão tentar jogar todos 
os desafios possíveis (sequencialmente) para finalizar todos, outros vão realizar apenas os que foram impostos para avançar no sistema. Por este motivo, o ambiente pode disponibilizar vários desafios e missões, para que o usuário permaneça motivado;

Medalhas/Conquistas: Medalhas são uma versão mais robusta de pontos e tratam-se de uma representação visual de alguma realização/conquista do usuário no sistema (Werbach e Hunter, 2012). Os usuários querem receber medalhas dentro de um ambiente por diversos motivos, para muitos, o objetivo é a experiência agradável de receber a medalha ou por "colecionar" medalhas. Do ponto de vista dos designers, as medalhas são uma forma de encorajar promoção social dos produtos e serviços;

Narrativa: Através da narrativa pode-se fazer com que o usuário apresente um comportamento esperado frente a um contexto. Histórias são utilizadas para transmitir informações e guiar pessoas, a combinação do sistema com a história cria uma experiência interativa que engaja o usuário (p.3-5).

Destaque-se que a reformulação da ferramenta 'Exercício' fará com que ele deixe de ser um formulário para se tornar um jogo educativo, ou seja, ao invés de simples perguntas com opções a serem escolhidas pelo aluno, passará a ter imagens, histórias, questões práticas a serem resolvidas por etapas, etc. Cada uma dessas formas de interação integrará o corpo do jogo.

Para modelar a nova ferramenta educacional, o jogo deve se pautar nas técnicas supracitadas, sendo a projeção lúdica imperceptível para o aluno e um mecanismo de avaliação para professores e tutores. Na prática, o estudante irá evoluir sem perceber que está aprendendo e sendo acompanhado pelos orientadores.

Sugere-se como primeira técnica de ludificação a implementação de pontos de experiência, que pode ser concretizada através do número de exercícios concluídos pelo aluno, ou seja, cada vez que uma tarefa for terminada este obtém um número pré-fixado de experiência, como 5 pontos, por exemplo. Assim, a cada novo exercício resolvido o estudante aumenta sua experiência e esta ficará diretamente vinculada ao nível do jogo.

Este, por seu turno, também é outra técnica de ludificação sugerida neste trabalho, posto que, além de fazer o aluno perceber que está aprendendo mais e evoluindo, também possibilita ao orientador (professor ou tutor) acompanhar a evolução de cada um dos participantes do curso. Dependendo do nível de desenvolvimento da ferramenta também se pode verificar as maiores dificuldades e facilidades encontradas durante a resolução do exercício, ou melhor, enquanto soluciona os desafios do jogo. 
Outra técnica de ludificação sugerida neste trabalho é a criação de pontos de habilidades. Estes são determinados de forma muito precisa para que o orientador possa visualizar qual a aptidão do aluno dentro do contexto das múltiplas inteligências. Estas, por seu turno, são definidas por Howard Gardner da seguinte forma:

La teoría de las inteligências múltiples, por otro lado, pluraliza el concepto tradicional. Uma inteligência implica la habilidade necesaria para resolver problemas o para elaborar prodctos que son de importancia en um contexto cultural o en una comunidad determinada. La capacidad para resolver problemas permite abordar una situación en la cual se persigue um objetivo, así como determinar el camino adecuado que conduce a dicho objetivo. La creación de de un producto cultural es crucial en funciones como la adquisición y la transmisión del conocimiento o la expresión de las proprias opiniones o sentimientos. Los problemas a resolver van desde crear el final de una historia hasta antecipar um movimiento de jaque mate en ajedrez, pasando por remendar un edredón. Los prodctos van desde teorías científicas, hasta composiciones musicales, pasando por campañas políticas exitosas.

La teoría de las IM se organiza a la luz de los orígenes biológicos de cada cacidad para resolver problemas. Sólo se tratan las capacidades que son universales a la espécie humana. Aun así, la tendencia biológica a participar de una forma concreta de resolver problemas tiene que asociarse también al entorno cultural. Por ejemplo, el lenguaje, uma capacidad universal, puede manifestarse particularmente en forma de escritura en una cultura, como oratoria en otra cultura y como el lenguaje secreto de los anagramas en una tercera (Gardner, Melero, 1995. p.4-5).

Gardner afirma que o conceito de inteligência é mais amplo do que se imaginava, tendo o ser humano aptidões inatas de acordo com suas características biológicas próprias, assim, foram identificadas pelo pesquisador sete tipos de inteligência, quais sejam: musical; cinético-corporal; lógico-matemática; linguística; espacial; interpessoal; intrapessoal. Em breve explanação define-se cada uma delas.

A inteligência musical é a habilidade que a pessoa tem para aprender a tocar instrumentos musicais, compor partituras etc. É uma espécie de inteligência auditiva. A cinético-corporal relacionase com o corpo, a habilidade de memorizar passos de dança, praticar esportes, dominar artes manuais etc. Esta apitdão é ampla e está associada ao domínio hábil do corpo, podendo se desenvolver de formas variadas.

A inteligência lógico-matemática é a habilidade de trabalhar com muitas variáveis de forma rápida, ou seja, conseguir resolver problemas complexos com pensamento matemático, associar, equacionar etc. Também se caracteriza pela capacidade de abstração, ou seja, transformar qualquer 
coisa em um raciocínio lógico. Por isso, esta disposição pode se expandir por muitos campos, como, por exemplo, as ciências em geral, a computação, a física etc.

A habilidade em linguística é a mais comum de todas, entretanto, é também complexa. Apesar de todos dominarem algum idioma, não são todas as pessoas que possuem facilidade em aprender várias linguagens e suas variações étnicas. Ademais, as pessoas com essa inteligência podem naturalmente desenvolver a capacidade da oratória erudita, o domínio de regras gramaticais, a interpretação de leituras de textos e o domínio de múltiplas línguas.

A inteligência espacial é a aptidão para compreender os espaços físicos, ou seja, é a habilidade de perceber distâncias e tamanhos, o que leva o indivíduo a ter facilidade com a navegação de embarcações, transportes, desenvolvimento de projetos de engenharia, nas artes visuais etc. As pessoas cegas demonstram claramente este tipo de inteligência, posto que podem se locomover medindo distâncias através do som, por exemplo.

No que cinge à inteligência interpessoal é o que comumente se chama de empatia. A pessoa com esta inteligência desenvolvida é capaz de observar e perceber a personalidade e estado de humor de outras pessoas. Os indivíduos com esta habilidade altamente evoluída conseguem praticamente ler o pensamento dos outros, antecedendo ações e reações com uma precisão impressionante. Este tipo de inteligência é comum entre líderes religiosos, políticos, vendedores.

Por fim, a inteligência intrapessoal é aquela relacionada à capacidade de conhecimento interno, o acesso e entendimento da própria vida emocional, dos aprendizados empíricos e o modo de compreender a si mesmo e suas emoções. São geralmente pessoas consideradas sábias, altamente maduras e inteligentes. Estas pessoas dificilmente influenciam-se pelo meio onde estão inseridas, pois teem uma compreensão tão grande de si mesmas que sabem exatamente o que é melhor para elas (Gardner, Melero, 1995).

Embora existam sete modalidades de inteligências, isto não significa que cada pessoa só pode ter um único tipo, não consiguindo desenvolver as demais. Na realidade, a ludificação tenta ampliar a capacidade cerebral estimulando todas elas, o que leva o aluno a pensar e aprender de uma forma completamente inusitada, como ele jamais havia aprendido antes. 
Assim, para inserir os pontos de habilidade é necessário inserir outra técnica de ludificação, que é a narrativa. Todo jogo, por mais simples que seja, explica através de uma narrativa como ele é, em qual contexto o jogador será inserido, quais as suas regras e como é possível vencê-lo.

Como o jogo objeto deste estudo é a ferramenta exercício, feita para fixar um conteúdo estudado na disciplina, esta narrativa deve ser elaborada com a inserção de textos dinâmicos, com situações-problema que serão solucionadas pelo aluno.

Em uma atividade com ludificação no curso de pedagogia, por exemplo, o estudante ao entrar na página do exercício verá um desenho animado de uma sala de aula, com lousa, carteiras, alunos, etc. Ouvirá sons que indicam o comportamento de crianças e perceberá que tipo de ferramentas disponíveis no ambiente poderão ser utilizadas para fazer atividades, fazer a turma ficar concentrada etc. O jogo inserirá conceitos próprios da pedagogia, como behaviorismo, dentre outros, para desafiar o cursista e ao mesmo tempo avaliar suas aptidões e deficiências. Se este observar comportamentos dos alunos e ignorar sons, por exemplo, o sistema poderá avaliá-lo como possuidor de inteligência interpessoal, mas ainda deficiente em musical. Para cada ação do jogador será atribuída uma pontuação de habilidade e ao final do exercício, no caso a partida do jogo, o aluno perceberá suas deficiências e poderá melhorá-las, além de fornecer ao orientador (professor ou tutor) o seu perfil.

Este é um exemplo de interação unicamente entre o aluno e o sistema, mas sugere-se outras técnicas de ludificação para estimular a interação. Para isto, os desafios e os pontos de carma são as técnicas mais apropriadas.

No ambiente do jogo haverá missões a serem cumpridas para que o aluno possa concluir todas as etapas e encerrar a partida. Contudo, cada missão exigirá pontos de carma para que as próximas fases sejam desbloqueadas, sendo estes obtidos quando o jogador ajuda um colega da sua turma a realizar as tarefas dele.

Nessa perspectiva, o jogo estimula o altruísmo e o espírito de equipe, aspectos fundamentais para o desenvolvimento humano. Associado a isto se insere a última técnica de ludificação sugerida neste trabalho, que é a obtenção de medalhas. Estas são um reconhecimento social do desempenho do aluno que, meritoriamente, as recebeu. Os melhores alunos, ou seja, aqueles que concluíram 
todos os exercícios no tempo mais rápido, receberão medalhas de ouro, por exemplo. Os que concluíram todos os exercícios, mas não tiveram um bom tempo, receberão medalha de prata, e assim sucessivamente, até não receber nenhuma medalha.

Após esta etapa de identificação das técnicas, foi possível sugerir a proposta de remodelação da ferramenta, onde se afirmou que o exercício, caso sejam implementados esses elementos de ludificação, deixa de ser um formulário para se tornar um jogo educativo com imagens, histórias, questões práticas a serem resolvidas por etapas, dentre outras.

\section{CONSIDERAÇÕES FINAIS}

Este trabalho teve como objetivo propor técnicas de ludificação existentes e utilizadas em ambientes virtuais de educação como as mais indicadas para a alteração da ferramenta exercício, dos cursos ofertados via EaD pela UECE. Demonstrou-se que o nível de aprendizado, segundo estudos retrocitados, pode aumentar em pelo menos $25 \%$ com a inclusão de técnicas de ludificação nos AVAs, o que justifica a necessidade de modernização da ferramenta em análise a fim de aumentar o engajamento e aprendizado dos alunos que a utilizam.

Verificou-se também que é possível utilizar as técnicas de ludificação para identificar e desenvolver os sete tipos de inteligência definidos pela psicologia moderna. Isto gera um impacto direto não somente no aprendizado do conteúdo que está sendo estudado, mas, também, na sua própria forma de aprender. A ludificação pode incentivar o desenvolvimento de outras inteligências, superando suas limitações cognitivas.

Foram identificadas e propostas sete técnicas, quais sejam: os pontos de experiência; os níveis do jogo; os pontos de habilidade; a narrativa; os desafios e missões; os pontos de carma; e as medalhas. 
O texto trouxe definições teóricas claras e suscintas sobre o que é um ambiente virtual de aprendizagem, o que é ludificação, como esta pode ser empregada nos ambientes virtuais, a partir de alguns conceitos e modelos da teoria dos jogos e propôs as técnicas acima que podem ser inseridos na ferramenta 'Exercícios', no AVA, tornando-a mais dinâmica, interativa e cativante para o aluno.

Por fim, este trabalho é uma proposta conceitual para auxiliar na remodelação da ferramenta pedagógica "exercício", encontrada no AVA da UECE. Futuramente, pesquisadores na área de programação poderão nortear-se por este modelo para elaborar um projeto de jogo e desenvolvê-lo em linguagem de programação.

\section{REFERÊNCIAS BIBLIOGRÁFICAS}

ALMEIDA, Marcela Alves de, 2014. Ambientes interativos: a relação entre jogos e design para a interação. 253f. Tese (Doutorado) - Núcleo de Pós-Graduação em Arquitetura e Urbanismo, Universidade Federal de Minas Gerais, Belo Horizonte.

BBVA INNOVATION EDGE, 2012. Gamification: The business of fun. Madrid: BBVA Innovation Center.

BIERMAN, H. Scott; FERNANDEZ, Luis, 2011. Teoria dos Jogos. 2a Ed. São Paulo: Pearson

CARVALHO, Marcelo Sávio Revoredo Menezes, 2006. A trajetória da Internet no Brasil: do surgimento das redes de computadores à instituição dos mecanismos de governança. 261f. Tese (Doutorado) - Núcleo de Pós-graduação em Engenharia, Universidade Federal do Rio de Janeiro, Rio de Janeiro.

ECK, Richard Van, 2006. Digital game-based learning: It's not just the digital natives who are restless. EDUCAUSE review, v. 41, n. 2, p. 16. 
FARDO, Marcelo Luis, 2013. A Gamificação aplicada em ambientes de aprendizagem. RENOTE, v. 11, n. 1.

FARDO, Marcelo Luís, 2014. A gamificação como estratégia pedagógica: estudo de elementos dos games aplicados em processos de ensino e aprendizagem. Dissertação de Mestrado. Universidade de Caxias do Sul.

GARDNER, Howard; MELERO NOGUÉS, María Teresa (traductor), 1995. Inteligencias múltiples: la teoria en la práctica. Barcelona: Paidós.

KIM, Jung Tae; LEE, Won-Hyung, 2013. Dynamical Model and Simulations for Gamification of Learning. International Journal of Multimedia and Ubiquitous Engineering, v. 8, n. 4, p. 179190.

KLOCK, Ana Carolina Tomé, et. al., 2014. Análise das técnicas de Gamificação em Ambientes Virtuais de Aprendizagem. RENOTE. v. 12, n. 2.

MARTINS, T.; NERY FILHO, J.; VIEIRA, F.; PONTES, E, 2014. A Gamificação de conteúdos escolares: uma experiência a partir da diversidade cultural brasileira. In: X Seminário de Jogos Eletrônicos, Educação e Comunicação. Anais do X Seminário de Jogos Eletrônicos, Educação e Comunicação. Salvador.

MORENO, Julián; PINEDA, Andrés F.; MONTOYA, Luis F. Minerva, 2015. Ludificación con Manejo de Errores Conceptuales en Sistemas de Gestión de Aprendizaje. Conferencias LACLO, v. 5, n. 1. 
MUNHOZ, Antonio Siemsen, 2013. O estudo em ambiente virtual de aprendizagem: um guia prático.

Curitiba: InterSaberes.

QUADROS, Gerson Bruno Forgiarini de, 2013. Gamificando os processos de ensino na rede. In: Anais do Congresso Nacional Universidade, EAD e Software Livre.

RAU, Maria Cristina Trois Dorneles, 2012. A ludicidade na educação: uma atitude pedagógica. Curitiba: Editora Saberes.

ROQUE, Alexandre dos Santos; SANTOS, Cristina Paludo; GEISS, Eno, 2013. GameLearning e suas Contribuições ao Ambiente Virtual de Aprendizagem Moodle. Revista Nuevas Ideas en Informática Educativa TISE.

SANTINELLO, Jamile, 2015. Ensino superior em ambientes virtuais de aprendizagem (AVAs): formação docente universitária em construção. Paraná: Editora Intersaberes.

ZICHERMANN, Gabe; CUNNINGHAM, Christopher, 2011. Gamification by Design. Implementing Game Mechanics in Web and Mobile Apps. Canada: O'ReillyMedia. 